\title{
Control, forecasting and optimisation for wave energy conversion *
}

\author{
John V. Ringwood* Giorgio Bacelli* Francesco Fusco** \\ * Centre for Ocean Energy Research, National University of Ireland, \\ Maynooth, Ireland (e-mail: john.ringwood@eeng.nuim.ie). \\ ** Smarter Cities Technology Centre, IBM Research Ireland, (e-mail: \\ francfus@ie.ibm.com)
}

\begin{abstract}
This paper presents an overview of the motivation, background to and state-ofthe-art in energy maximising control of wave energy devices. The underpinning mathematical modelling is described and the control fundamentals established. Two example control schemes are presented, along with some algorithms for wave forecasting, which can be a necessary requirement, due to the non-causal nature of some optimal control strategies. One of the control schemes is extended to show how cooperative control of devices in a wave farm can be beneficial. The paper also includes perspectives on the interaction between control and the broader objectives of optimal wave energy device geometry and full techno-economic optimisation of wave energy converters.
\end{abstract}

Keywords: Wave energy, control, optimisation, power maximisation, wave forecasting

\section{INTRODUCTION}

With the recent sharp increases in the price of oil, issues of security of supply, and pressure to honor greenhouse gas emission limits (e.g. the Kyoto protocol), much attention has turned to renewable energy sources to fulfil future increasing energy needs. Wind energy, now a mature technology, has had considerable proliferation, with other sources, such as biomass, solar and tidal enjoying somewhat less deployment. Wave provide previously untapped energy potential and wave energy has been shown to have some favourable variability properties (a perennial issue with many renewables, especially wind), especially when combined with wind energy (Fusco et al., 2010).

The main reason for the lack of proliferation of wave energy is that harnessing the irregular reciprocating motion of the sea is not as straightforward as, say, extracting energy from the wind. Wind energy turbine design has, in the main, converged on a generic device form, the 3-bladed horizontal axis turbine, and turbine technology and its associated control systems are well developed.

Nevertheless, it is interesting to note that, as solar energy is subsequently converted into wind and then waves, the power density increases. For example, at a latitude of 15 $\mathrm{N}$ (Northeast trades), the solar insolation is $0.17 \mathrm{~kW} / \mathrm{m}^{2}$. However the average wind generated by this solar radiation is about 20 knots $(10 \mathrm{~m} / \mathrm{s})$, giving a power intensity of $0.58 \mathrm{~kW} / \mathrm{m}^{2}$ which, in turn, has the capability to generate waves with a power intensity of $8.42 \mathrm{~kW} / \mathrm{m}^{2}$ (McCormick, 1981). The distribution of wave energies worldwide is depicted in Fig.1. One of the interesting characteristics of the wave energy distribution is that some countries with a relatively high dependence on imported fossil fuels

* Part of this work was supported by Enterprise Ireland and the Irish Research Council

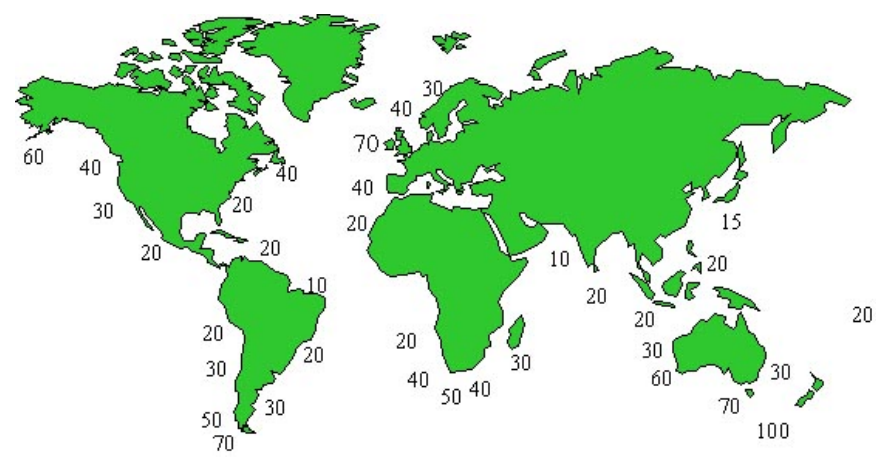

Fig. 1. Outline global wave map (Thorpe, 1998)

for electricity production (e.g. Ireland at 88\% in 2008) have access to a significant wave energy resource (70 $\mathrm{kW} / \mathrm{m}$ of wave crest). As a case in point, Ireland has a practical annual wave resource of $14 \mathrm{TWh}$, with an annual consumption of just under double that at $26 \mathrm{TWh}$. However, a mitigating factor is that the wave resource is frequently located a significant distance from consumption centers, an issue also highlighted with other renewable resources (Knight, 2008).

The current poor state of wave energy technology development is highlighted by the availability of just a few commercially available wave energy converters (WECs), including the Wave Dragon (Soerensen, 2003), Pelamis (Yemm et al., 2002), Oyster (Whittaker and Folley, 2012) and Wavestar (Kramer et al., 2011). The stark contrast in operational principle of these four devices, as well as the diversity in appearance and operation of the 147 prototypes listed in (Koca et al., 2013) provides further evidence of the relative immaturity of wave energy technology. Drew et al. (2009) provide a useful overview of wave energy devices and technology classification. 
In addition to the relative lack of progress in basic WEC design there is, understandably, a corresponding 'fertile field' in the development of control system technology to optimize the operation of wave energy devices. This article will attempt to show that the availability of such control technology is not only necessary, but vital, if WECs are to be serious contenders in the renewable energy arena. Ultimately, energy conversion must be performed as efficiently as possible in order to minimize delivered energy cost, while also:

- Maintaining the structural integrity of the device;

- Minimising wear on WEC components, and

- Operating across a wide variety of sea conditions.

Dynamic analysis and control system technology can impact many aspects of WEC design and operation, including:

- Device sizing and configuration;

- Maximisation of energy extraction from waves, and

- Optimising the energy conversion in the power takeoff (PTO) system.

Ultimately, commissioned wave energy devices or 'farms' must provide energy at prices which are competitive with, at least, other renewable sources. In the short term, a number of state agencies, including Portugal and Ireland, have provided inflated tariffs to stimulate the development and proliferation of wave energy devices, at $0.23 / \mathrm{kWh}$ and $0.22 / \mathrm{kWh}$ respectively. As a benchmark for comparison, the cost of domestic electricity in Ireland is currently $0.14 / \mathrm{kWh}$. Some recent analysis suggests that current costs for wave energy are in the region of Euro $1 / \mathrm{kWh}$ (Babarit and Hals, 2011).

As a measure of the challenge, since energy density increases by a factor of almost 15 in the conversion from wind to wave, one might expect that wave devices should be 15 times smaller than their wind counterparts, for a comparable power output. However, a typical conventional 850 $\mathrm{kW}$ horizontal axis wind turbine (e.g. Vestas V52-850 kW) has a tower height of $60 \mathrm{~m}$ and a rotor diameter of $52 \mathrm{~m}$, while the Pelamis (rated at $750 \mathrm{~kW}$ ) has a length of $150 \mathrm{~m}$ and a diameter of $3.5 \mathrm{~m}$. This rough comparison suggests that we still have a considerable way to go. However, since raw renewable resources (wind, wave, etc) are free, the predominant economic performance metric (Weber et al., 2013) for wave energy is the cost of energy delivered to the grid.

In making wave energy extraction economic, the control community has a significant role to play. While much work remains to be done on optimising the basic geometry of WECs and the development of efficient power takeoff (PTO) systems, it is already clear that appropriate control technology has the capability to double the energy take from WECs (Babarit and Clement, 2006). However, the control problem is not one which fits neatly into a traditional form (e.g. setpoint following) though, for some special cases e.g. potable water production, more traditional regulation loops are required (Bacelli et al., 2009). In addition, servo loops are often required in hierarchical WEC control (see Section 4).

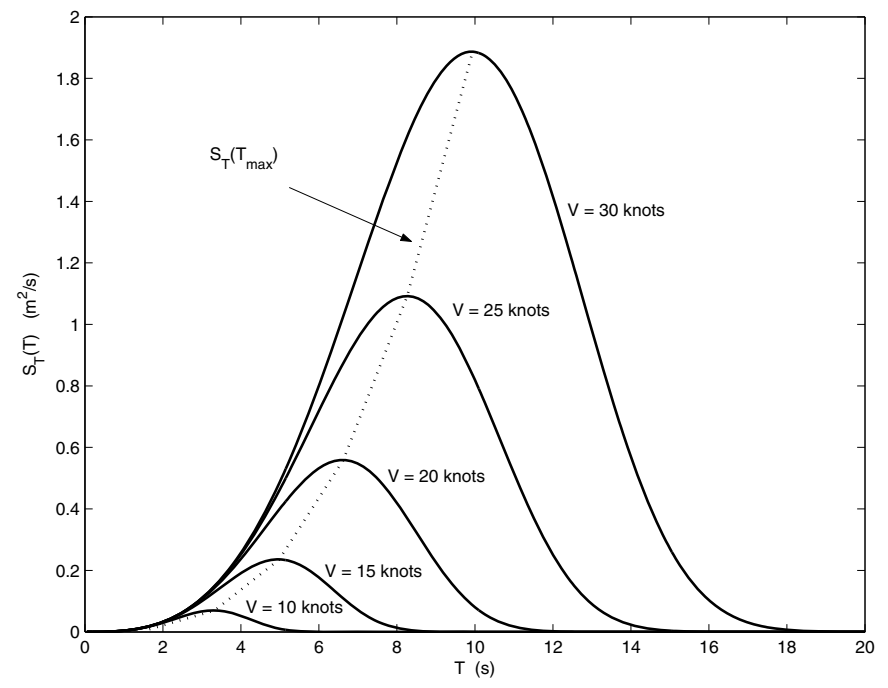

Fig. 2. Typical Pierson-Moskowitz wave spectra
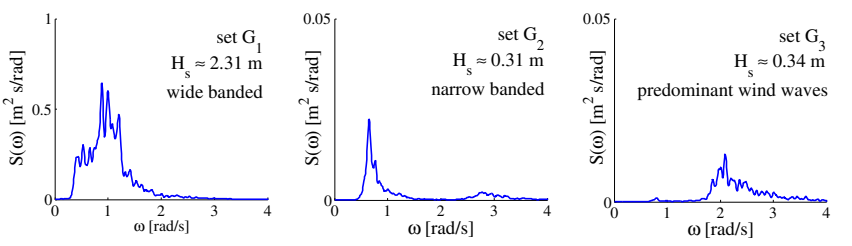

Fig. 3. Real wave spectrum

The objective of this article is to articulate the 'control' problem associated with WECs, examine the structure of a typical WEC model and give some examples of how control and associated technologies can be applied to WECs and WEC arrays. An overview of the forecasting problem associated with non-causal control strategies is also given, along with some sample forecasting results.

\section{QUANTIFYING THE WAVE RESOURCE}

The two measurable properties of waves are height and period. With regard to wave height, researchers and mariners found that observed wave heights did not correspond well to the average wave height, but more to the average of the one-third highest waves. This statistically averaged measure is termed the significant wave height and usually denoted as $H_{\frac{1}{3}}$ or $H_{s}$. In addition, real ocean waves do not generally occur at a single frequency. Rather, a distributed amplitude spectrum is used to model ocean waves, with random phases. The use of energy spectra to represent sea states has been enumerated by a number of researchers, including Bretschneider (Bretschneider, 1952) and Pierson, Moskowitz (Pierson and Moskowitz, 1964) and the spectra resulting from the JONSWAP project (K. Hasselmann et al, 1973). Both the Bretschneider and Pierson-Moskowitz spectra have the general form of:

$$
S_{T}(T)=A T^{3} e^{-B T^{4}}
$$

for the wave spectral density (or wave spectrum), $S_{T}(T)$, with the coefficients $A$ and $B$ for the Pierson-Moskowitz model, by way of example, given as: 


$$
\begin{aligned}
& A=8.10 \times 10^{-3} \frac{g^{2}}{(2 \pi)^{4}} \\
& B=0.74\left(\frac{g}{2 \pi V}\right)^{4}
\end{aligned}
$$

where $V$ is the wind velocity measured $19.5 \mathrm{~m}$ above the still water level (SWL), $g$ is the acceleration due to gravity and $T$ is the wave period in seconds. Some typical wave spectra generated from the Pierson-Moskowitz model are shown in Fig.2. Note that the available wave energy increases (approximately) exponentially with wave period, $T$.

It should be noted that not all waves are well represented by the spectral models of the type shown in (1). In some cases, where swell and local wind conditions are relatively uncorrelated (which can often be the case, for example, on the West Coast of Ireland (ESB International, 2005)), 'split spectra', consisting of spectra containing two distinct peaks, can occur. A variety of spectral shapes are illustrated in Fig.3 and present a significant challenge to the WEC designer and control engineer alike.

Note also that all of these previously mentioned wave spectra models are for fully developed waves i.e. the fetch (the distance over which the waves develop) and the duration for which the wind blows are sufficient for the waves to achieve their maximum energy for the given wind speed. In addition, linear wave theory is assumed i.e. we assume that waves are well represented by a sinusoidal form. This relies on the following two assumptions:

- There are no energy losses due to friction, turbulence, etc., and

- The wave height, $H$ is much smaller than the wavelength, $\lambda$.

However, it can be seen that not only is the 'windwave' component in Fig.3 for set $G_{3}$ at odds with the Pierson-Moskowitz model spectrum shown in Fig.2, but there are three distinct low frequency components in set $G_{1}$. Directional wave analysis (Gilloteaux and Ringwood, 2009) can be used to reveal the individual components. In general, with regard to wave directionality,

- Directional wave devices are tethered with nondirectional moorings which allow the devices to face the predominent wave direction, or

- Devices are non-directional, such as heaving buoytype devices.

However, there are a number of exceptions to this general rule, including shore-mounted oscillating water column devices, and while many devices can be considered nondirectional, the (fixed) moorings to which they are attached are rarely truly non-directional.

In general a wave spectrum is assumed to be stationary for up to 3 hours. Time-frequency analysis, utilising the Wavelet transform (Nolan et al., 2007) can be used to examine spectral variability and, for longer durations (e.g. a year), wave scatter diagrams (see Fig.4) provide a joint probability table of significant wave heights and characteristic periods for a particular wave site. For example, the data shown in Fig.4 shows two predominant wave climates which exist at a particular site.

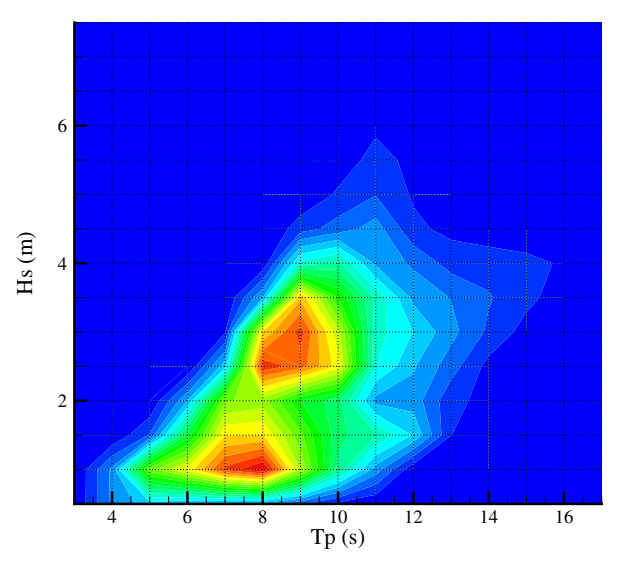

Fig. 4. Scatter diagram for typical wave energy site

The energy in an ocean wave, consisting of both potential and kinetic energy, is proportional to the square of the wave amplitude McCormick (1981) and proportional to the wavelength, as:

$$
E_{w}=E_{p}+E_{k}=\frac{\rho g H^{2} \lambda b}{8}
$$

where $H$ is the wave height above SWL, $\lambda$ is the wavelength, $\rho$ the water density and $b$ the crest width. In deep water, the energy in a linear wave is equally composed of potential energy (exhibited by the wave height) and kinetic energy (dependent on the motion of the particles) as:

$$
E_{p}=E_{k}=\frac{\rho g H^{2} \lambda b}{16}
$$

For simulation purposes, wave spectra are usually discretized and individual sinusoidal components used, where the amplitudes are determined from the spectral density (e.g. as in Fig.2), and random initial phases employed for individual components.

\section{MATHEMATICAL MODELS FOR WAVE ENERGY DEVICES}

Mathematical models of wave energy devices are required for a variety of purposes:

(1) Assessment of power production

(2) Assessment of loading/forces under extreme sea conditions

(3) Simulation of device motion, including evaluating the effectiveness of control strategies, and

(4) For use as a basis for model-based control design.

Mathematical models for wave energy devices should, ideally, encompass the water/device (hydrodynamic) interactions and PTO system, and may also include a model for connection to an electrical grid, thus presenting a total 'wave-to-wire' model (Josset et al., 2007). While the PTO and grid (or possible other downstream energy consumers, such as reverse osmosis) may be modelled using more traditional physical, lumped parameter, modelling methodologies, the determination of the hydrodynamic model for a WEC, or array of WECs, is nontrivial. A variety of modelling methodologies are available, most of which involve the solution to partial differential equations across a numerical mesh. 


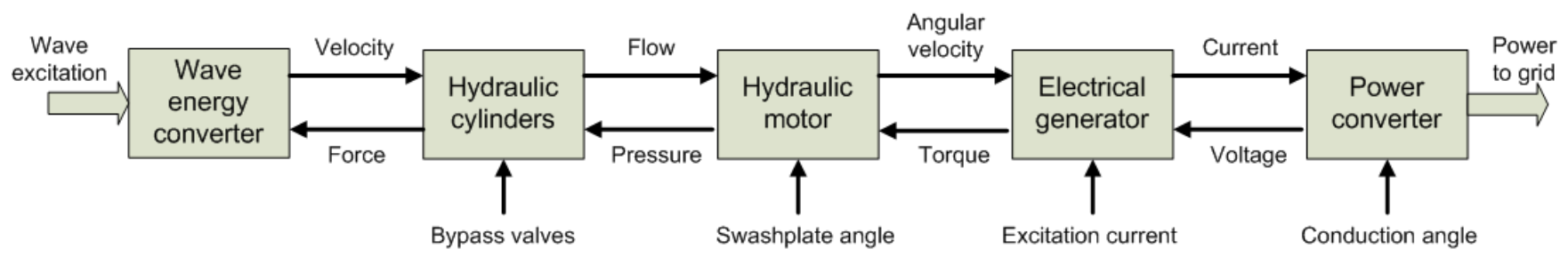

Fig. 5. Wave energy PTO system components and potential control inputs

Among the possible hydrodynamic solvers with the highest fidelity are algorithms based on smooth particle hydrodynamics (SPH) (Cleary et al., 2007) or computational fluid dynamics (CFD) (Agamloh et al., 2008). Such approaches can articulate the full range of nonlinear hydrodynamic forces in three dimensions. However, given the significant computational overhead of such approaches (typically a second of simulation time takes around an hour of computation time), they are not ideal either as a basis for modelbased control design, nor as a simulation tool to evaluate the effectiveness of various control designs. However, they have been used to develop simpler parametric models, which can provide a basis for control design and simulation (Davidson et al., 2013). The remainder of this section is primarily devoted to the development of hydrodynamic models. An outline of a possible PTO system is shown in Fig.5 and shows the possible inclusion of mechanical, hydraulic and electrical components. In many cases, for example for the SeaBased device (Trapanese, 2008), the WEC is directly coupled to a linear generator, eliminating the hydraulic components. Given the many potential changes of energy form evident from Fig.5, bond graphs have been shown to be a powerful tool in providing a systematic graphical procedure to determine mathematical models for wave energy PTO systems (Bacelli et al., 2008), or complete wave energy systems (Hals, 2010).

\subsection{Linear models and Cummins' equation}

Consider a single-body floating system oscillating in heave, as shown in Fig.6. Energy is extracted from the relative motion with the sea bottom, through a generic PTO mechanism. The external forces acting on the WEC are the excitation from the waves and the control force produced by the PTO, namely $f_{e x}(t)$ and $f_{u}(t)$. Additional hydrodynamic and hydrostatic forces arising due to the motion of the body in the water, are the radiation force, $f_{r}(t)$, the diffraction force, $f_{d}(t)$, the viscous force, $f_{v}(t)$, the mooring force, $f_{m}(t)$, and the buoyancy, $f_{b}(t)$ (Falnes, 2002). The equation of motion, following Newton's second law and where a superposition of forces is assumed, in one degree of freedom, is specified as:

$$
\begin{array}{r}
M \dot{v}(t)=f_{m}(t)+f_{r}(t)+f_{d}(t)+f_{v}(t)+ \\
f_{b}(t)+f_{e x}(t)+f_{u}(t),
\end{array}
$$

where $v(t)$ is the heaving velocity and $M$ is the WEC mass.

With the assumptions of linear potential theory (Falnes, 2002), namely:

(1) irrotational, incompressible and inviscid fluid,

(2) small-body approximation (wave elevation constant across the whole body),

(3) small oscillations (constant wetted surface),

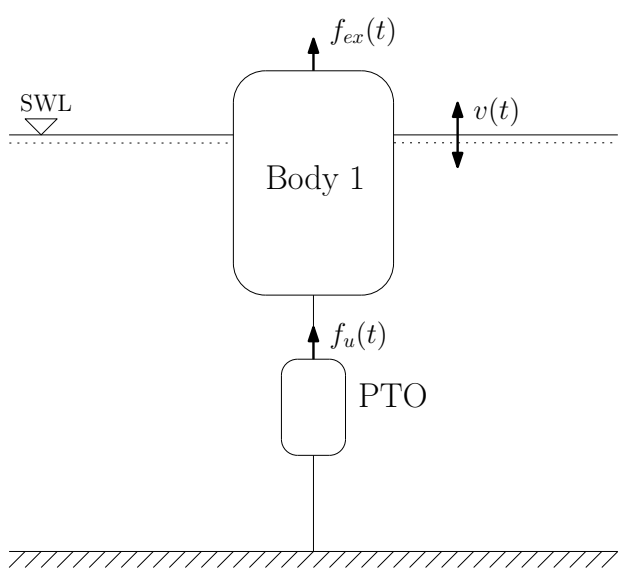

Fig. 6. One-degree of freedom floating system for wave energy conversion.

the following simplifying equations apply:

$$
\begin{aligned}
& f_{e x}+f_{d}(t)=\int_{-\infty}^{+\infty} h_{e x}(\tau) \eta(t-\tau) d \tau \\
& f_{r}(t)=-\int_{0}^{t} h_{r}(\tau) v(t-\tau) d \tau-m_{\infty} \dot{v}(t) \\
& f_{b}(t)=-\rho g S_{w} \int_{0}^{t} v(\tau) d \tau=-K_{b} x(t) \\
& f_{v}(t)=0 .
\end{aligned}
$$

In (7), the excitation (and diffraction) force is related to the incident wave, $\eta(t)$, through the excitation kernel function $h_{e x}(t)$. Eq. (8) expresses the radiation force as a linear convolution of the radiation kernel, $h_{r}(t)$, with the oscillation velocity $v(t)$, while $m_{\infty}$ is the added mass infinite frequency asymptote. The buoyancy force, $f_{b}(t)$, models the hydrostatic equilibrium, related to the heaving position through a linear coefficient that depends on the gravity acceleration, $g$, the water density, $\rho$ and the surface area of the body cut by the mean water level, $S_{w}$. Note the non-causality of the expression for the excitation force, where $h_{e x}(t) \neq 0$ for $t \leq 0$ (Falnes, 2002). Eq. (6), excluding the mooring force $f_{m}(t)$ and the viscous damping force $f_{v}(t)$ results in the popular Cummins' equation (Cummins, 1962):

$$
\begin{array}{r}
\left(M+m_{\infty}\right) \dot{v}(t)+\int_{0}^{+\infty} h_{r}(\tau) v(t-\tau) d \tau+K_{b} x(t)= \\
\int_{-\infty}^{t} h_{e x}(\tau) \eta(t-\tau) d \tau
\end{array}
$$

Typically, $h_{e x}(t)$ and $h_{r}(t)$ are calculated numerically using boundary-element potential methods such as WAMIT 
(WAMIT, 2002), which performs the calculations in the frequency domain, or ACHIL3D (Clement, 2009), where time domain calculations are used. Eq.(11) can also be used to model multi-body systems (Bacelli and Ringwood, 2013b) or arrays of devices (Bacelli and Ringwood, 2013a), with the modification that the dimensions of $M, m_{\infty}, K$ and the hydrodynamic parameters represented by $h_{e x}(t)$ and $h_{r}(t)$ all increase in dimension accordingly.

\subsection{Modelling higher-order hydrodynamic effects}

The linear model shown in (11) assumes:

- Sinusoidal waves (or a summation of),

- No viscosity effects, and

- No vortex shedding.

In addition, the boundary element methods used to compute $h_{e x}(t)$ and $h_{r}(t)$ assume:

- Small waves,

- Small device motion (displacement and velocity), and

- Infinite device height.

In particular, while the assumption of small device motion is usually a reasonable one for systems contained within a regulatory loop (which tries to maintain the system output at a reference point), this assumption is not one which is well satisfied in the case of WECs, since it is normally the objective to exaggerate the motion (e.g. through resonance) in order to maximise power capture. Finally, current boundary element solvers typically used a fixed mesh, though some new approaches are now appearing which propose the use of adaptive meshes (Lee, 2012). However, the computational effort increases considerably with adaptive meshing.

Ideally, we should take into account nonlinear device motion and therefore interactions between the:

- Incident wave field,

- Diffraction potential, and

- Radiation potential

potentially resulting in coupling between different motions, which can demonstrate parametric resonance effects (Villegas and van der Schaaf, 2011). In addition, account can be taken of possible device submergence using potential methods, but not wave breaking effects, since effects are calculated only from a 'potential' point of view.

Numerical methods for partial or fully nonlinear hydrodynamic modelling have been developed (Beck and Reed, 2001) and several commercial software packages are already on the market such as FREDYN (De Kat and Pauling, 1989) and LAMP (Lin and Kuang, 2011). Among these latter methods, one possible extension of the lineartime domain model is to compute the nonlinear FroudeKrylov forces on the undisturbed wetted surface while diffraction-radiation forces remain linear or are expanded up to the second-order (Gilloteaux, 2007; Gilloteaux et al., $2008)$. Hence, the hydrodynamic force $\tau_{H}$ may be decomposed into six terms:

$$
\tau_{H}=\tau_{B}+\tau_{F K}+\tau_{R a d}^{(1)}+\tau_{D i f f}^{(1)}+\tau_{R a d}^{(2)}+\tau_{D i f f}^{(2)}
$$

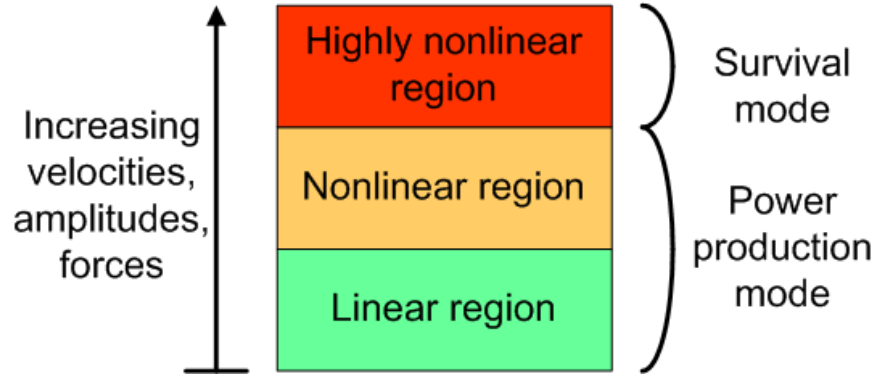

Fig. 7. WEC operational modes and nonlinear behaviour

where indexes (1) and (2) denote the first and secondorder solutions for both diffraction and radiation force. For example, the study by Merigaud et al. (2012) calculates Froude-Krylov forces both on the instantaneous and exact wetted surfaces to compare the power production figures for linear and nonlinear WEC models. The assumption is that the Froude-Krylov forces are large compared to diffraction and radiation forces, which are modelled using linear terms. The study by Merigaud et al. (2012) clearly shows that linear models overestimate WEC motion for large wave excitation. A slightly alternative formulation is presented by Guerinel et al. (2011). However, the difficulty of employing such approaches is the need for re-calculation of hydrodynamic parameters at each simulation step, rendering such methods computationally inappropriate as a basis for model-based control, though they could possibly be used for high-fidelity simulation.

If desired, nonlinear viscous forces can be added (e.g. to (11)) using a term experimentally derived by Morison et al. (1950), as:

$$
f_{v}(t)=\rho R C_{d}|v(t)| v(t)
$$

for a cylindrical shape, where $\rho$ is the water density, $R$ is the cylinder radius and $C_{d}$ is the drag coefficient. Empirical validations of the Morison equation have proven its validity and methods have been proposed to evaluate the coefficient $C_{d}$ for certain specific shapes (Bhinder et al., 2012; Yuan and Huang, 2010). In addition, a linear approximation to (13) may be derived, using an energy matching technique (Bacelli et al., 2013), if desired.

In addition, nonlinear PTO effects, such as saturation, non-ideal efficiency and other static nonlinearities could be considered, but are beyond the scope of this review, given the wide variety of PTO system components available.

Fig.7 considers nonlinear effects within the context of overall WEC operation. As the motion becomes more exaggerated, nonlinear effects become more predominant. However, from a control perspective, this is only an issue within the power production mode. Beyond a 'safe' operating region, supervisory control is normally used to put the device into survival mode, which limits motion and allows extreme wave forces to be tolerated while maintaining device integrity.

\subsection{Radiation damping approximations}

Typically, for both simulation and control applications, the radiation damping convolution term in (8) is replaced by a closed form (finite order) equivalent. This has the following advantages: 
- The integro-differential equation in (11) is replaced by a higher-order differential equation, making analysis more straightforward,

- The resulting finite-order dynamical system is faster to simulate, and

- The closed-form dynamical equation can be used as a basis for model-based control design.

In general, $h_{r}(t)$ (and it's Fourier transform, $H_{r}(\omega)$ ) are nonparametric in form, being the result of a numerical calculation on a distributed system. Approximations can be determined in either the time- or frequency-domain, depending on the manner in which $h_{r}(t) \leftrightarrow H_{r}(\omega)$ was determined, and the intended (time/frequency domain) use of the finite-order approximation. For example, WAMIT (WAMIT, 2002) uses a frequency-domain analysis to determine $H_{r}(\omega)$ directly and approximations based on WAMIT data are usually based on frequency-domain error criteria. In such a case, state-space forms (Perez and Fossen, 2007) or transfer function forms (McCabe et al., 2005) may be determined using frequency-domain identification (Levy, 1959).

Alternatively, if $h_{r}(t)$ is directly produced, for example from the time domain code ACHIL3D (Clement, 2009), time-domain impulse-response fitting can be employed, typically using Prony's method (Prony, 1795). In general, an order 4-10 linear approximation to $h_{r}(t)$ is used, for both time- and frequency-domain approaches. Taghipour et al. (2008) provides an overview of, and background to, the calculations of finite order approximations to $h_{r}(t) \leftrightarrow$ $H_{r}(\omega)$. These authors also consider finite-order approximation to the excitation force kernel, $h_{e x}(t)$ (with Fourier transform $F_{e x}(\omega)$ ), as does McCabe et al. (2005).

\section{WAVE ENERGY CONTROL FUNDAMENTALS}

In order to consider the control problem for wave energy devices, it is pertinent to attempt a definition of the control objective:

\section{Maximise Performance objective (max. energy) \\ subject to: Constraints (amplitudes, forces, etc)}

Ignoring system constraints for the moment, we can make a start on the energy maximisation problem by considering the force-to-velocity model of a WEC, which is obtained from (11) in the frequency domain Falnes (2002):

$$
\frac{V(\omega)}{F_{e x}(\omega)+F_{u}(\omega)}=\frac{1}{Z_{i}(\omega)},
$$

where $Z_{i}(\omega)$ is termed the intrinsic impedance of the system. In $(14), V(\omega), F_{e x}(\omega)$ and $F_{u}(\omega)$ represent the Fourier transform of the velocity, $v(t)$, excitation force, $f_{\text {ex }}(t)$ and control force $f_{P T O}(t)$, respectively. Note that, in the following, unless stated otherwise, the Fourier transform of time-domain signals or functions will be denoted by the corresponding capital letter, namely $X(\omega) \triangleq \mathcal{F}\{x(t)\}$.

The intrinsic impedance, $Z_{i}(\omega)$, of the model in (14) is specified as (refer to Falnes (2002) for the full derivation):

$$
Z_{i}(\omega)=B_{r}(\omega)+\jmath \omega\left[M+M_{a}(\omega)-\frac{K_{b}}{\omega^{2}}\right],
$$

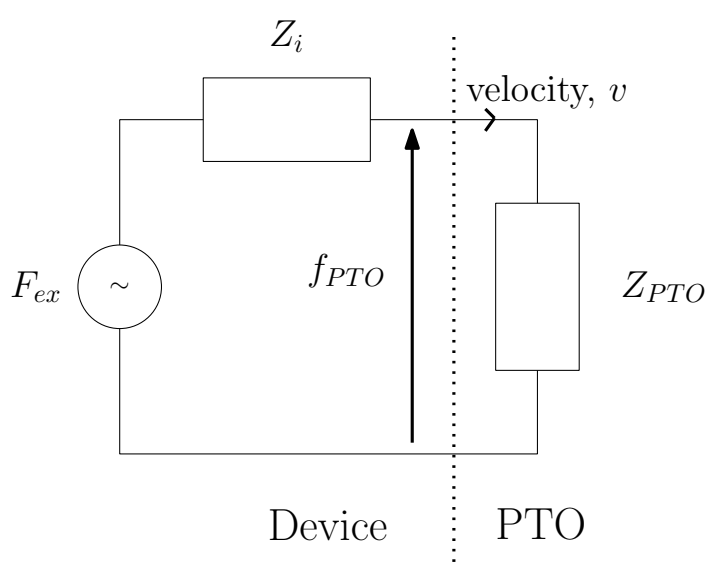

Fig. 8. Impedance matching

where $B_{r}(\omega)$ is the radiation resistance (real and even) and $m_{\infty}$ is the added mass.

The model in (14) allows the derivation of conditions for optimal energy absorption and the intuitive design of the energy maximising controller in the frequency domain Falnes (2002) as:

$$
Z_{P T O}(\omega)=Z_{i}^{*}(\omega)
$$

where ()$^{*}$ denotes the complex conjugate. The choice of $Z_{P T O}$ as in (16) is referred to as complex conjugate control, but many (especially electrical) engineers will recognise this choice of $Z_{P T O}$ as the solution to the impedance matching problem represented by Fig.8. The result in (16) has a number of important implications:

- It is frequency dependent, implying that there is a different optimal impedance for each frequency - how to specify for irregular seas containing a mixture of frequencies?

- Since $h_{r}(t)$ is causal, $h_{c}(t)=\mathcal{F}^{-1}\left(Z_{P T O}(\omega)\right)$ is anticausal, requiring future knowledge of the excitation force. While this is straightforward for the monochromatic case (single sinusoid), it is more problematic for irregular seas. The issue of forecasting random seas is dealt with in Section 6.

- Since force and velocity can have opposite signs in Fig.8, the PTO may supply power for some parts of the sinusoidal cycle. This is akin to reactive power in power systems. Such a phenomenon places particular demands on PTO systems, not only in terms of the need to facilitate bi-directional power flow, but also that the peak reactive power can be significantly greater than active power (Shek et al., 2008; Zurkinden et al., 2013). The optimal passive PTO is provided by $R_{P T O}=\left|Z_{i}(\omega)\right|$, which avoids the need for the PTO to supply power, but results in a suboptimal control.

- The optimal control in (16) takes no account of physical constraints in the WEC/PTO, where there are likely to be limitations on displacement or relative displacement, PTO force and there may be external constraints imposed by electrical grid regulations.

The condition in (16) can alternatively be expressed in terms of an optimal velocity profile as:

$$
V^{\text {opt }}(\omega)=F_{\text {ex }}(\omega) /\left(2 R_{i}(\omega)\right)
$$




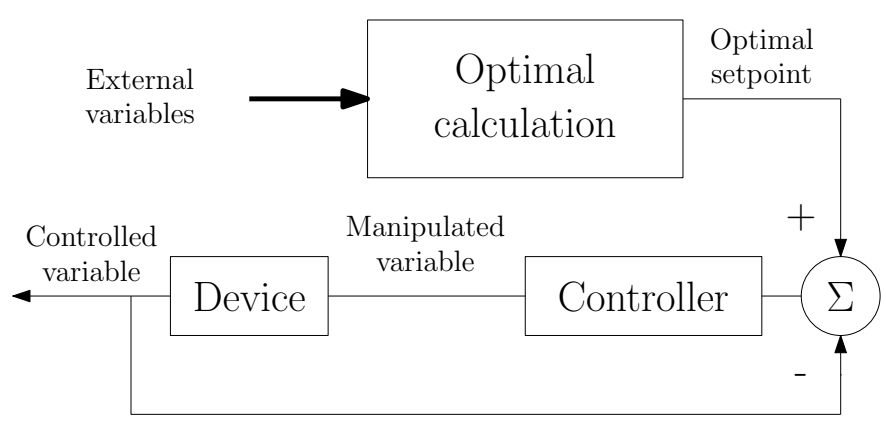

Fig. 9. Hierarchical control structure

where $R_{i}=1 / 2\left(Z_{i}+Z_{i}^{*}\right)$ is the real part of $Z_{i}$. The condition in (17) is a condition on the amplitude of $V^{o p t}(\omega)$, with the restriction that $v^{o p t}(t)$ be in phase with $f_{e x}(t)$, since $R_{i}$ is a real (and even) function. This phase condition, considered separately, forms the basis for some simple WEC phase control strategies, such as latching (Budal and Falnes, 1975; Korde, 2002; Babarit and Clement, 2006) and de-clutching (Babarit et al., 2009; Teillant et al., 2010; Wright et al., 2003).

While the conditions of (16) and (17) specify the optimal device velocity profile, they don't specify how it might be achieved. Fig. 9 shows a hierarchical structure for WEC control, where the optimal velocity is calculated in the upper branch and the PTO force is used to achieve this velocity in the lower servo loop. Fig.9 highlights the calculation of the optimal velocity profile as an open loop calculation, which is therefore sensitive to modelling errors. There is therefore a robustness issue to be addressed, which is considered in Section 5.1. It is interesting to note that the control structure of Fig.9 is also utilised by most wind turbine controllers, where the optimum power coefficient $C_{p}$ is determined from blade pitch angle $\beta$ and tip speed ratio $\lambda$, and generator torque control is then typically used to achieve the tip speed ratio that maximises $C_{p}$, where $C_{p}=f_{\text {turbine }}(\beta, \lambda)$ (Leithead and Connor, 2000).

\subsection{Control effectors}

Since wave energy PTO systems typically involve a number of changes of energy form, there can be a variety of ways to implement the required $f_{P T O}$, in order to achieve the desired device velocity. Fig.5 shows a number of possible variables which can be manipulated to control the PTO force which opposes the WEC device motion, including:

- Hydraulic motor swashplate angle,

- Generator excitation current, and

- Power converter conduction angle.

In general, only one of these inputs is used, though consideration of efficiency of the various included PTO components might suggest that some combination might be beneficial. An additional input, for WECs where multiple hydraulic cylinders or (linear) electrical generators are used, could be the number of cylinders/generators employed either on a wave-to-wave basis, or for significant changes in sea state. Hydraulic bypass valves would be used to deactivate hydraulic cylinders, while non-required linear generators could be electrically short-circuited. A final control possibility is that of pumpable water ballast, which can be used to alter the WEC inertia and therefore change its resonant frequency (which is predominantly related to $M$ and $K_{b}$ in (11)). An example study using ballast control for a bottom-hinged flap was performed by Qiu et al. (2013). However, the use of water ballast as a control input has limitations, including maximum pumping rate (determined by pump size) and the energy cost of moving water ballast.

\section{REAL-TIME CONTROL OF WAVE ENERGY CONVERTERS}

This section shows two possibilities for real-time control of WECs, both of which handle system constraints. They are at opposite ends of the complexity/performance spectrum, so provide a reasonable indicator of the range of WEC control algorithms available.

\subsection{Simple (but effective) control}

Consider (17), which calculates the optimal velocity profile as a (frequency dependent) function of the excitation force for the system as shown in Fig.6. In the following, a nonoptimal approximation of reactive control is proposed, where the non-causality and constraints are handled in a simple, but effective, way. The essence of this algorithm is the assumption that $f_{e x}(t)$ is a narrow-banded harmonic process, defined by time-varying amplitude, $A(t)$, frequency, $\omega(t)$, and phase $\varphi(t)$ :

$$
f_{e x}(t)=A(t) \cos (\omega(t) t+\varphi(t))
$$

the optimal reference velocity can then be generated from the following adaptive law:

$$
v_{r e f}(t)=\frac{1}{H(t)} f_{e x}(t), \quad \frac{1}{H(t)}=\frac{1}{2 R_{i}(\hat{\omega})}
$$

where the value of the constant $H(t)$ is calculated from the curve $1 / 2 B(\omega)$, based on a real-time estimate of the peak frequency of the wave excitation force. An on-line estimate of the frequency, $\hat{\omega}$, and amplitude, $\hat{A}$, is obtained with the extended Kalman filter (EKF) (Quine et al., 1995). Based on the narrow-banded assumption of (18), the excitation force can be expressed in complex notation as:

$$
f_{e x}(t)=\Re\left\{A e^{\jmath \varphi} e^{\jmath \omega t}\right\}, \quad \hat{F}_{e x} \triangleq A e^{\jmath \varphi},
$$

where $\hat{F}_{e x}$ is the complex amplitude of $f_{e x}(t)$.

As a consequence of the proportional reference-generation law in (19), the complex amplitude of the velocity, $\hat{V}$, and position, $\hat{U}$, can be expressed as:

$$
\begin{aligned}
& \hat{V}=\frac{A}{H} e^{\jmath \varphi} \\
& \hat{U}=\frac{\hat{V}}{\jmath \omega}=\frac{A}{\jmath \omega H} e^{\jmath \varphi} .
\end{aligned}
$$

Suppose that the vertical excursion of the WEC is limited to $\pm U_{\text {lim }} \mathrm{m}$ from equilibrium. From (22), the position constraint can be written as an equivalent velocity constraint:

$$
\hat{U}=\frac{\hat{V}}{\jmath \omega} \leq U_{\text {lim }} \quad \Leftrightarrow \quad|\hat{V}| \leq \omega U_{\text {lim }}
$$

and the following upper bound for the variable gain, $1 / H$, involving the amplitude and frequency of the excitation, can be derived from (21) as:

$$
\frac{1}{H} \leq \frac{\omega U_{l i m}}{A} .
$$




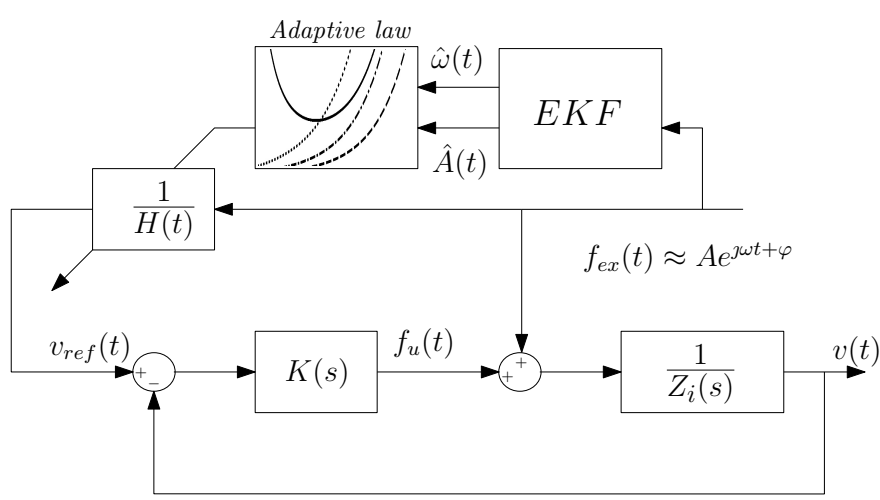

Fig. 10. Proposed control architecture.

The reference generation strategy, based on (17), (19) and (24) can therefore be modulated in order to keep the amplitude of the velocity within the bound specified in (23). A real-time estimate of the frequency, $\hat{\omega}$, and amplitude, $\hat{A}$, of the excitation, can be obtained through the EKF (Budal and Falnes, 1982; Fusco and Ringwood, 2010):

$$
\frac{1}{H(t)}= \begin{cases}\frac{1}{2 R_{i}(\hat{\omega})}, & \text { if } \frac{\hat{\omega} U_{\text {lim }}}{\hat{A}}>\frac{1}{2 R_{i}(\hat{\omega})} \\ \frac{\omega U_{\text {lim }}}{\hat{A}}, & \text { otherwise }\end{cases}
$$

According to (25), when in the unconstrained region, the velocity is tuned to the optimal amplitude given by complex-conjugate control, as in (17). Otherwise, the maximum allowed velocity (lower than the optimal) is imposed, while keeping the velocity in phase with the excitation force. The control structure is illustrated in Fig.10. Since the algorithm is only loosely based on the WEC model, it has relatively good robustness properties to model error. Lower loop control, as illustrated in Figs.9 and 10 is performed using internal model control (IMC) (Morari and Evanghelos, 1989), while a robust servo controller has been developed by Fusco and Ringwood (in press). The simple controller, when compared with a model predictive controller (MPC) in both wide- and narrow-banded seas, has a relative capture with within about $10 \%$ of the MPC, but has superior robustness to variations in $K_{b}$. Further details on this controller are given in (Fusco and Ringwood, 2013).

\subsection{An MPC-like control algorithm}

This control solution is based on the discretization, in the time domain, of the PTO force and of the motion of the device in order to transform the problem into a Non Linear Program (NLP). The approach is similar to the direct simultaneous method used for the solution of optimal control problems (Cuthrell and Biegler (1987)), where both the control variables and the state variables are discretized. The main steps are documented here, with more complete details available in (Bacelli et al., 2011). The application considered is the general two-body device shown in Fig.11. Consistent with the desire to maximise converted energy, we specify a performance function of the form:

$$
J(T)=\int_{0}^{T} f_{p t o}(t)\left(v^{A}(t)-v^{B}(t)\right) d t
$$

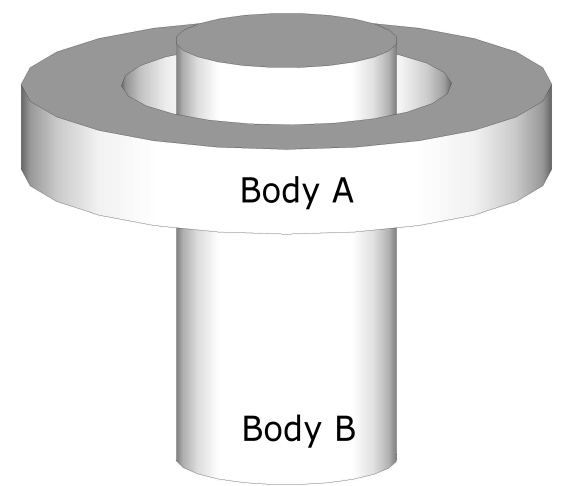

Fig. 11. Two body self-reacting device

where the vertical velocities of body $A$ and body $B$ are denoted $v^{A}(t)$ and $v^{B}(t)$, respectively. The system model, which includes interactions between the two bodies is:

$$
\left\{\begin{aligned}
L^{A}(t)=m^{A} \dot{v}^{A}(t) & +B^{A} v^{A}(t)+S^{A} u^{A}(t) \\
& -f_{e}^{A}(t)-f_{r}^{A}(t)+f_{p t o}(t)=0 \\
L^{B}(t)=m^{B} \dot{v}^{B}(t) & +B^{B} v^{B}(t)+S^{B} u^{B}(t) \\
& -f_{e}^{B}(t)-f_{r}^{B}(t)-f_{p t o}(t)=0
\end{aligned}\right.
$$

where the hydrostatic buoyancy is described by $S^{A}$ and $S^{B}$ while $B^{A}$ and $B^{B}$ are terms describing the linear viscous loss. The excitation forces on body $A$ and body $B$ are denoted by $f_{e}^{A}$ and $f_{e}^{B}$, respectively. We wish to find the optimal profile of the PTO force $\left(f_{\text {pto }}\right)$ in a given time interval of length $T$ that maximizes the absorbed energy $J(T)$ as defined in (26), subject to:

$$
\left\|u^{A}(t)-u^{B}(t)\right\|_{\infty} \leq \Delta U_{\max },
$$

The PTO force is assumed to be such that $f_{\text {pto }}(t) \in$ $L^{2}([0, T])$, where $L^{2}([0, T])$ is the Hilbert space of square integrable functions in the interval $[0, T]$; also $v^{A}(t), v^{B}(t) \in$ $L^{2}([0, T])$ because they are velocities of physical bodies. The PTO force and the velocities are then approximated as a linear combination of basis functions in a finite dimensional subspace of the space $L^{2}([0, T])$ :

$$
\begin{aligned}
v^{A}(t) & \approx \hat{v}^{A}(t)=\sum_{j=1}^{N} x_{j}^{A} \phi_{j}(t) \\
v^{B}(t) & \approx \hat{v}^{B}(t)=\sum_{j=1}^{N} x_{j}^{B} \phi_{j}(t) \\
f_{p t o}(t) & \approx \hat{f}_{p t o}(t)=\sum_{j=1}^{N^{P}} p_{j} \phi_{j}^{P}(t)
\end{aligned}
$$

For any given set of coefficients describing the PTO force $\left\{p_{1}, \ldots, p_{N^{P}}\right\}$, the components of the velocities are calculated by solving the system:

$$
\left\{\begin{array}{l}
\left\langle L^{A}(t), \phi_{j}\right\rangle=0 \\
\left\langle L^{B}(t), \phi_{j}\right\rangle=0
\end{array} \quad \forall j=1, \ldots N\right.
$$

where $\langle\cdot, \cdot\rangle$ denotes the inner product. Using the approximations in (29) to (31) and choosing Fourier series for the basis, (27) can be written (Bacelli et al., 2011) as:

$$
\left[\begin{array}{ll}
G^{A A} & G^{A B} \\
G^{B A} & G^{B B}
\end{array}\right]\left[\begin{array}{l}
X^{A} \\
X^{B}
\end{array}\right]=\left[\begin{array}{l}
E^{A} \\
E^{B}
\end{array}\right]+\left[\begin{array}{c}
-I_{2 N} \\
I_{2 N}
\end{array}\right] P
$$

where $I_{2 N}$ is the identity matrix of size $2 N$, and 


$$
\begin{aligned}
X^{A} & =\left[a_{1}^{A}, b_{1}^{A}, a_{2}^{A}, b_{2}^{A}, \ldots, a_{N}^{A}, b_{N}^{A}\right]^{T}, \\
X^{B} & =\left[a_{1}^{B}, b_{1}^{B}, a_{2}^{B}, b_{2}^{B}, \ldots, a_{N}^{B}, b_{N}^{B}\right]^{T}, \\
E^{A} & =\left[e_{1}^{A_{c}}, e_{1}^{A_{s}}, e_{2}^{A_{c}}, e_{2}^{A_{s}}, \ldots, e_{N}^{A_{c}}, e_{N}^{A_{s}}\right]^{T}, \\
E^{B} & =\left[e_{1}^{B_{c}}, e_{1}^{B_{s}}, e_{2}^{B_{c}}, e_{2}^{B_{s}}, \ldots, e_{N}^{B_{c}}, e_{N}^{B_{s}}\right]^{T}, \\
P & =\left[a_{1}^{p}, b_{1}^{p}, a_{2}^{p}, b_{2}^{p}, \ldots, a_{N}^{p}, b_{N}^{p}\right]^{T},
\end{aligned}
$$

with $E^{A, B}$ are the set of excitation force coefficients. Note that $G=\left[\begin{array}{cc}G^{A A} & G^{A B} \\ G^{B A} & G^{B B}\end{array}\right]$ contains hydrodynamic coefficients corresponding to the terms in (27). The performance function in (26) can now be rewritten as:

$$
J(P)=-P^{T} H P+P^{T}\left(Q^{A} E^{A}-Q^{B} E^{B}\right)
$$

where $H$ and $Q^{A, B}$ are functions of the elements of $G$. It can be shown that $H$ is positive definite; therefore, the quadratic cost function (34) is concave and the global maximum of the unconstrained problem is obtained for:

$$
\bar{P}=\left(H+H^{T}\right)^{-1}\left(Q^{A} E^{A}-Q^{B} E^{B}\right) .
$$

We solve the constrained optimization problem:

$$
\max _{P} J(P) \quad \text { subject to }\|\Delta u\|_{\infty} \leq \Delta U_{\max }
$$

using the penalty method (Nocedal and Wright, 2006); the constrained maximization problem (36) is therefore reformulated as the unconstrained minimization problem

$$
\min _{P}-J(P)+\mu \max \left\{0,\|\Delta u\|_{\infty}-\Delta U_{\max }\right\}
$$

where $\mu>0$ is the penalty parameter. The optimization problem is solved by starting with $\mu_{1} \ll 1$, which corresponds to the unconstrained problem; if the solution violates the constraint then $\mu_{k}$ is updated as $\mu_{k+1}=\alpha \mu_{k}$ with $\alpha>1$, and the new solution $P_{k+1}^{*}$ is calculated. If the constraint is satisfied, the algorithm stops, otherwise the process is repeated until the solution is found.

For this control study, the feedback controller (as shown in Fig.9) was obtained by solving a continuous time LQ tracking problem.

Other MPC-like WEC control algorithms have been presented by Hals et al. (2010); Cretel et al. (2010); Li and Belmont (2013). One of the chief difficulties in applying MPC to a performance function of the form of $(26)$ is that the performance function is, in general, non-convex. The closely related optimal LQG problem for wave energy devices has been studied by Scruggs et al. (2013).

\section{WAVE FORECASTING}

While some WEC control algorithms circumvent the need to predict future variations in free surface elevation or excitation force (Fusco and Ringwood, 2013; Scruggs et al., 2013), in general there is a need to provide forecast values of free surface elevation or excitation force due to the non-causality of the optimal PTO force, as articulated in Section 4. Fortunately, there is a strong positive connection between the wave forecasting requirements of energy maximising control (Fusco and Ringwood, 2012) and the forecastability of random seas (Fusco and Ringwood, 2010), due to the close relationship between the radiation damping dynamics and the design sea state (i.e. predominant period).

Wave forecasting can be performed using up-wave measurement (Monk et al., 2013) or time series modelling at the device location (Fusco and Ringwood, 2010), as shown in Fig.12. While many time series techniques may be
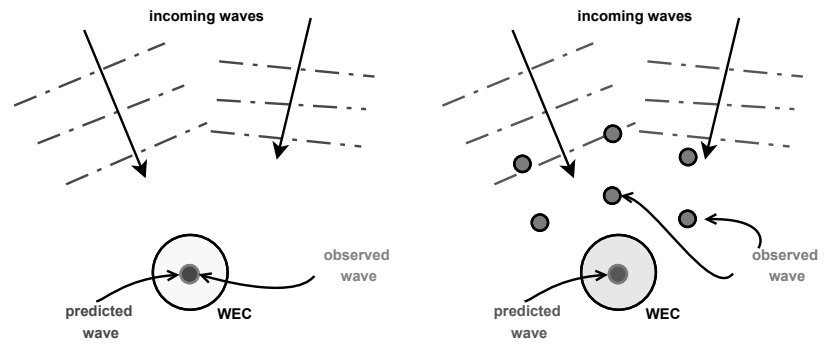

(a) Prediction based only on lo- (b) Prediction based on up-wave cal single-point measurements measurements

Fig. 12. The two main approaches to wave forecasting

employed, including harmonic, neural network and models based on the extended Kalamn filter, a simple linear autoregressive (AR) forecasting model, viz:

$$
\hat{\eta}(k+l \mid k)=\sum_{i=1}^{n} \hat{a}_{i}(k) \hat{\eta}(k+l-i \mid k),
$$

performs well and has a nice frequency domain interpretation. For example, Fig.13 shows $\hat{\eta}(k+l \mid k)$, for $l=1$ to $l=50$, at a specific time instant $k$, calculated with an AR model of order $n=24$ on the data set $P_{2}$, filtered with cutoff frequency $\omega_{c}=0.7 \mathrm{rad} / \mathrm{s}$ for wave data at Pico island in the Azores. Fig.14 shows how the AR model poles pick out the characterictic spectral peaks in the sea spectrum.

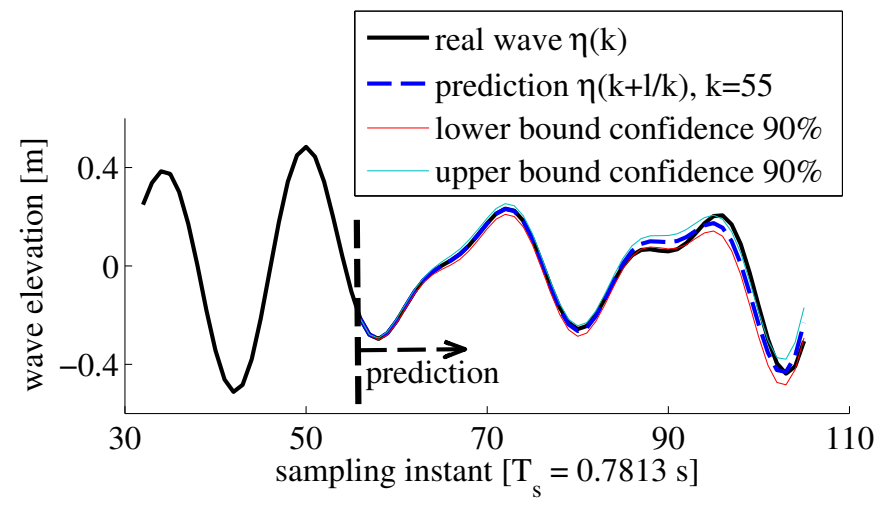

Fig. 13. Wave prediction and confidence intervals
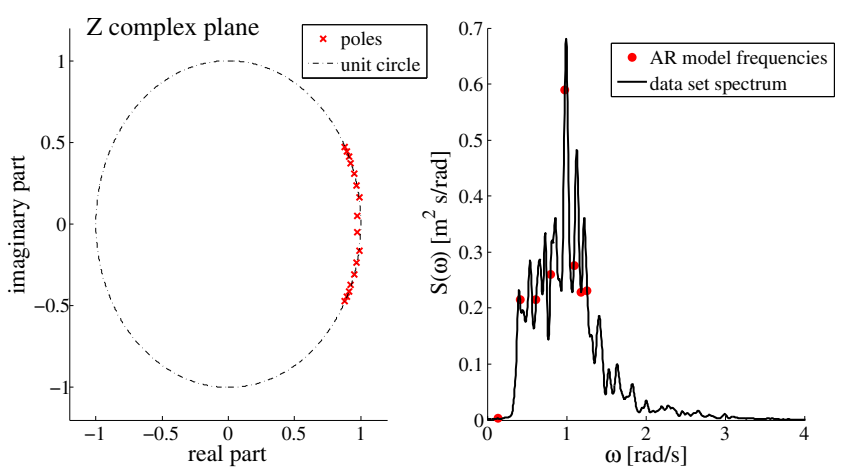

Fig. 14. AR model poles and sea spectrum 


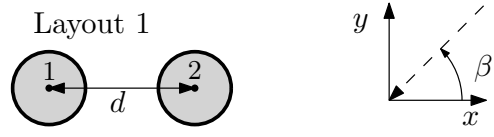

Layout 2

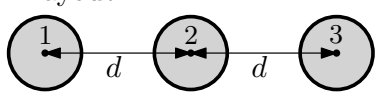

Fig. 15. Plan of array layouts and incident wave angle, $\beta$

\section{CONCLUSIONS AND PERSPECTIVES}

Researchers from a variety of disciplines have addressed the wave energy control problem since the 1970's. However, much work remains in order to develop control strategies which perform well over the complete WEC operational space, are robust to modelling errors and disturbances and have some fault-tolerant capability, since WECs are normally located in remote areas, with limited access. It is also estimated that, for wave farms, maintenance costs are likely to be the same order of magnitude as capital costs.

There are many new promising areas where control can make further contributions in wave energy applications, including cooperative control of arrays of wave energy devices (Bacelli et al., 2013; Bacelli and Ringwood, 2013a; $\mathrm{Li}$ and Belmont, 2013). For example, for the sample array layouts of Fig.15, Fig.16 shows the ratio $\left(E_{i} / E_{g}\right)$ of energy captured by an array of heaving cylinders (radius $=4 \mathrm{~m}$, draught $=10 \mathrm{~m}$ and resonance period $=7.1 \mathrm{~s}$ ) with independent device control $\left(E_{i}\right)$ and global coordinated control $\left(E_{g}\right)$ in a sea with peak period $T_{p}=12 s(\lambda=225 \mathrm{~m})$. The optimal control laws (roughly based on the algorithm in Section 5.2) for each WEC, in the case of independent control (IC), are obtained by iteration, during which time the estimator and predictor on each WEC builds up a reliable forecast of the incoming waves (reaching quasi steady state). This asymptotic condition is denoted by the lines marked with $*$. Though not feasible in practice, it provides an upper performance bound for the IC case. More realistically, the comparison between the global control (GC) and IC is also evaluated considering only the first iteration of the IC (marked with o). The GC is also based on the algorithm in Section 5.2; however, the control model in this case accounts for all hydrodynamic interaction between the devices in the array, resulting in up to $20 \%$ better energy capture than IC.

One important issue, highlighted by Gilloteaux and Ringwood (2010), is the strong interaction between the ideal WEC geometric shape and the WEC control strategy employed. This has lead to the consideration of total wave energy system optimisation, or techno-economic optimisation (Costello et al., 2012), illustrated in Fig.17, with the relaisation that, while energy or efficiency maximisation is an interesting academic and engineering problem, the most important metric for a wave energy system is the total economic benefit. However, articulation of detailed capital and operations costs for wave energy systems is non-trivial (Teillant et al., 2012). To date, the wave energy control problem has not received the full attention of the wider control systems community. There are a broad range of control technologies and algorithms which can have strong potential in the wave energy control application
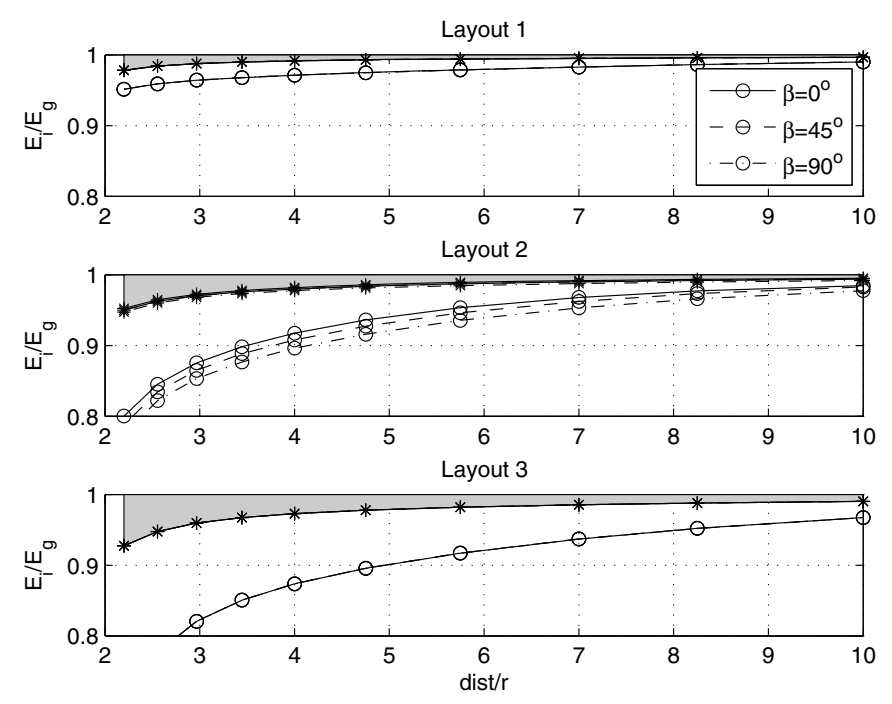

Fig. 16. Relative performance of IC and GC for an array of heaving cylinders

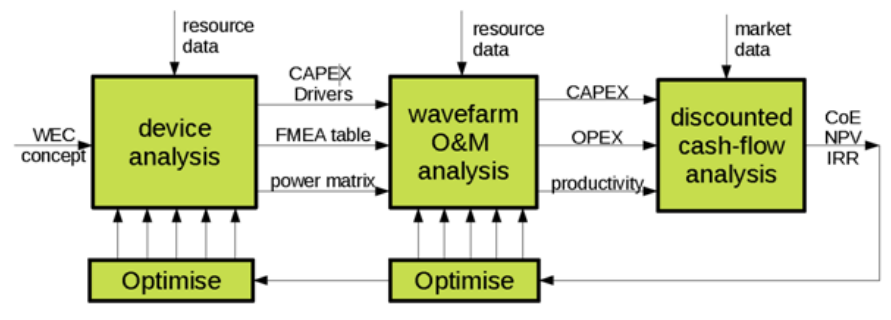

Fig. 17. Techno-economic optimisation philosophy

area and there are a number of application areas which are relatively mature from a control perspective and which bear a strong resemblance to the wave energy control problem. For example, the connection with wind turbine control was articulated in Section 4. The control of wave energy devices is a fertile control systems playground!

\section{REFERENCES}

Agamloh, E.B., Wallace, A.K., and von Jouanne, A. (2008). Application of fluid structure interaction simulation of an ocean wave energy extraction device. Renewable Energy, 33(4), 748-757.

Babarit, A. and Clement, A. (2006). Optimal latching control of a wave energy device in regular and irregular waves. Applied Ocean Research, 28, 77-91.

Babarit, A. and Hals, J. (2011). On the maximum and actual capture width ratio of wave energy converters. In Proc. $10^{\text {th }}$ European Wave Energy Conference.

Babarit, A., Guglielmi, M., and Clment, A.H. (2009). Declutching control of a wave energy converter. Ocean Engineering, 36(1213), 1015 - 1024.

Bacelli, G., Balitsky, P., and Ringwood, J. (2013). Coordinated control of arrays of wave energy devices benefits over independent control. IEEE Trans. on Sustainable Energy, 4, 1091-1099.

Bacelli, G., Gilloteaux, J.C., and Ringwood, J. (2008). State space model of a hydraulic power take off unit for wave energy conversion employing bondgraphs. In Proc. World Renewable Energy Conf. 
Bacelli, G. and Ringwood, J. (2013a). Constrained control of arrays of wave energy devices. In Proc. $11^{\text {th }}$ European Wave Energy Conference. Aalborg, Denmark.

Bacelli, G. and Ringwood, J. (2013b). A geometric tool for the analysis of position and force constraints in wave energy converters. Ocean Engineering, 65, 10-18.

Bacelli, G., Ringwood, J., and Gilloteaux, J.C. (2009). Control of a wave energy device for potable water production. In Proc. Euro. Control Conf., 3755-3760.

Bacelli, G., Ringwood, J., and Gilloteaux, J.C. (2011). A control systyem for a self-reacting point absorber wave energy converter subject to constraints. In Proc. IFAC World Congress, 11387-11392.

Beck, R. and Reed, A. (2001). Modern computational methods for ships in a seaway. Trans. Soc. of Naval Architects and Marine Eng., 109, 1-52.

Bhinder, M., Babarit, A., Gentaz, L., and Ferrant, P. (2012). Effect of viscous forces on the performance of a surging wave energy converter. In Proc. Conf. of the Intl. Society of Offshore and Polar Engineers (ISOPE), $545-550$.

Bretschneider, C. (1952). The generation and decay of wind waves in deep water. Trans. Am. Geophys. Union, 33, 381-389.

Budal, K. and Falnes, J. (1975). A resonant point absorber of ocean wave power. Nature, 256, 478-479.

Budal, K. and Falnes, J. (1982). The Norwegian wavepower buoy project. In The Second Intern. Symp. on Wave Energy Utillization, 323-344.

Cleary, P., Prakash, M., Ha, J., Stokes, N., and Scott, C. (2007). Smooth particle hydrodynamics: status and future potential. Progress in Computational Fluid Dynamics, 7, 70-90.

Clement, A. (2009). Using differential properties of the green function in seakeeping computational codes. In Proc. Euro. Control Conf., 3755-3760.

Costello, R., Teillant, B., Weber, J., and Ringwood, J. (2012). Techno-economic optimisation for wave energy converters. In Proc. Intl. Conf. on Ocean Energy.

Cretel, J., Lewis, A., Lightbody, G., and Thomas, G. (2010). An application of model predictive control to a wave energy point absorber. In Proc. IFAC Conf. on Control Methodologies and Technology for Energy Efficiency, 267-272.

Cummins, W. (1962). The impulse response function and ship motions. Schiffstechnik, 9, 101-109.

Cuthrell, J.E. and Biegler, L.T. (1987). On the optimization of differential-algebraic process systems. AIChE J., 33(8), 1257-1270.

Davidson, J., Giorgi, S., and Ringwood, J. (2013). Linear parametric hydrodynamic models based on numerical wave tank experiments. In 9th European Wave and Tidal Energy Conference (EWTEC), Aalborg.

De Kat, J. and Pauling, R. (1989). The simulation of ship motions and capsizing in severe seas. Trans. Soc. Naval Architects and Marine Eng.

Drew, B., Plummer, A., and Sahinaya, M. (2009). A review of wave energy converter technology. Proc. IMechE Part A: Power and Energy.

ESB International (2005). Accessible Wave Energy Resource Atlas: Ireland: 2005. The Marine Institute/Suatainable Energy Ireland.
Falnes, J. (2002). Ocean Waves and Oscillating Systems. Cambridge University Press, Cambridge, UK.

Fusco, F. and Ringwood, J. (2012). A study of the prediction requirements in real-time control of wave energy converters. IEEE Transactions on Sustainable Energy, 3(1), 176-184.

Fusco, F. and Ringwood, J. (2013). A simple and effective real-time controller for wave energy converters. IEEE Trans. on Sustainable Energy, 4, 21-30.

Fusco, F. and Ringwood, J. (in press). Hierarchical robust control of oscillating wave energy converters with uncertain dynamics. IEEE Trans. on Sustainable Energy.

Fusco, F., Nolan, G., and Ringwood, J.V. (2010). Variability reduction through optimal combination of wind/wave resources-an irish case study. Energy, 35(1), $314-325$.

Fusco, F. and Ringwood, J. (2010). Short-term wave forecasting for real-time control of wave energy converters. IEEE Trans. on Sustainable Energy, 1, no. 2, 99-106.

Gilloteaux, J.C. (2007). Simulation de mouvements de grande amplitude - application a la recouperation de l'energie des vagues. Ph.D. thesis, Ecole Centrale de Nantes.

Gilloteaux, J.C., Bacelli, G., and Ringwood, J.V. (2008). A non-linear potential model to predict large-amplitudesmotions: application to a multi-body wave energy converter. In Proc. 10th World Renewable Energy Conf.

Gilloteaux, J.C. and Ringwood, J. (2009). Influence of wave directionality on a generic point absorber. In Proc. 8th European Wave and Tidal Energy Conference, 979988. Uppsala, Sweden.

Gilloteaux, J.C. and Ringwood, J. (2010). Controlinformed geometric optimisation of wave energy converters. In Proc. IFAC Conf. on Control Applications in Marine Systems (CAMS), 399-404.

Guerinel, M., Alves, M., and Sarmento, A. (2011). Nonlinear modelling of the dynamics of a free floating body. In Proc. 10th European Wave and Tidal Energy Conference. Southampton, UK.

Hals, J. (2010). Modelling and phase control of wave energy converters. Ph.D. thesis, Norwegian University of Science and Technology.

Hals, J., Falnes, J., and Moan, T. (2010). Constrained optimal control of a heaving buoy wave-energy converter. J. Offshore Mech and Arctic Eng., 133, 011401.1-.15.

Josset, C., Babarit, A., and Clment, A.H. (2007). A wave-to-wire model of the searev wave energy converter. Proceedings of the Institution of Mechanical Engineers, Part M: Journal of Engineering for the Maritime Environment, 221(2), 81-93.

K. Hasselmann et al (1973). Measurements of windwave growth and swell decay during the joint north sea wave project (JONSWAP). Technical report, Deutschen Hydrographischen Institut, Hamburg, Germany.

Knight, H. (2008). Edison's revenge. New Scientist, $200(2677), 40$.

Koca, K., Kortenhaus, A., Oumeraci, H., Zanuttigh, B., Angelelli, E., Cantu, M., Suffredini, R., and Franceschi, G. (2013). Recent advances in the development of wave energy converters. In $9^{\text {th }}$ European Wave and Tidal Energy Conference (EWTEC). 
Korde, U. (2002). Latching control of deep water wave energy devices using an active reference. Ocean Engineering, 29(11), 1343-1355.

Kramer, M., Marquis, L., and Frigaard, P. (2011). Performance evaluation of the Wavestar prototype. In 10th European Wave and Tidal Energy Conference (EWTEC), Southampton.

Lee, S.C. (2012). A finite element boundary element method for infinite periodic structures on non-periodic meshes using an interior oenalty formulation. Ph.D. thesis, Ohio State University.

Leithead, W. and Connor, B. (2000). Control of variable speed wind turbines: design task. International Journal of Control, 73(13), 1189-1212.

Levy, E. (1959). Complex curve fitting. IRE Trans. on Automatic Control, AC-4, 37-43.

Li, G. and Belmont, M. (2013). Model predictive control of an array of wave energy converters. In 11th European Wave and Tidal Energy Conference, EWTEC.

Lin, R.Q. and Kuang, W. (2011). A fully nonlinear, dynamically consistent numerical model for solid-body ship motion. i. ship motion with fixed heading. Proceedings of the Royal Society A: Mathematical, Physical and Engineering Science, 467(2128), 911-927.

McCabe, A.P., Bradshaw, A., and Widden, M.B. (2005). A time-domain model of a floating body using transforms. In 6th Euro. Wave and Tidal Energy Conference.

McCormick, M. (1981). Ocean Wave Energy Conversion. Wiley.

Merigaud, A., Gilloteaux, J.C., and Ringwood, J. (2012). A nonlinear extension for linear boundary element methods in wave energy device modelling. In Proc. Intl. Conf. on Offshore Mechanics and Arctic Eng.

Monk, K., Conley, D., Lopez, M., and Zou, Q. (2013). Pneumatic power regulation by wave forecasting and real-time relief valve control for an owc. In 11th European Wave and Tidal Energy Conference (EWTEC).

Morari, M. and Evanghelos, Z. (1989). Robust Process Control. Prentice-Hall, Inc.

Morison, J.R., OBrien, M.P., Johnson, J.W., and Schaaf, S.A. (1950). The force exerted by surface waves on piles. AIME Petroleum Transactions, 189, 149-154.

Nocedal, J. and Wright, S.J. (2006). Numerical Optimization. Springer, New York, 2nd edition.

Nolan, G., Ringwood, J., and Holmes, B. (2007). Short term wave energy variability off the west coast of ireland. In Proc. rth Euro. Wave and Tidal Energy Conf. Porto.

Perez, T. and Fossen, T. (2007). Time-domain models of marine surface vessels for simulation and control design based on seakeeping computations. In Proc. of the 7th IFAC Conf. on Manoeuvring and Control of Marine Craft $(M C M C)$.

Pierson, W. and Moskowitz, L. (1964). A proposed spectral form for fully developed wind seas based on the similarity theory of S.A. Kitaigorodskii. J. Geophys. Res., 69, 5181-5190.

Prony, R. (1795). Essai exprimental et analytique: Sur les lois de la dilatabilit des fluides lastiques et sur celles de la force expensiver de la vapeur del'eau et de la vapeur de l'alkool, diffrentes tempratures. Paris J. l'Ecola Polytechnique, 1, 24-76.

Qiu, S.q., Ye, J.w., Wang, D.j., and Liang, F.l. (2013). Experimental study on a pendulum wave energy converter.
China Ocean Engineering, 27(3), 359-368.

Quine, B., Uhlmann, J., and Durrant-Whyte, H. (1995). Implicit jacobians for linearised state estimation in nonlinear systems. In Proc. of the American Control Conf., 1645-1646.

Scruggs, J., Lattanzio, S., Taflanidis, A., and Cassidy, I. (2013). Optimal causal control of a wave energy converter in a random sea. Applied Ocean Research, $42(0), 1-15$.

Shek, J., Macpherson, D., and Mueller, M. (2008). Phase and amplitude control of a linear generator for wave energy conversion. In 4th IET Conf. on Power Electronics, Machines and Drives (PEMD), 66-70.

Soerensen, H. (2003). Development of wave dragon from scale 1:50 to prototype. In Proc. $5^{\text {th }}$ Euro. Wave Energy Conf., 110-116. HMRC, Cork.

Taghipour, R., Perez, T., and Moan, T. (2008). Hybrid frequency time domain models for dynamic response analysis of marine structures. Ocean Engineering, 35, 685-705.

Teillant, B., Gilloteaux, J.C., and Ringwood, J. (2010). Optimal damping profile for a heaving buoy wave energy converter. In IFAC Conf. on Control Applications in Marine Systems (CAMS), 393-398.

Teillant, B., Costello, R., Weber, J., and Ringwood, J. (2012). Productivity and economic assessment of wave energy projects through operational simulations. Renewable Energy, 48, 220-230.

Thorpe, T. (1998). An Overview of Wave Energy Technologies. ETSU.

Trapanese, M. (2008). Optimization of a sea wave energy harvesting electromagnetic device. Magnetics, IEEE Transactions on, 44(11), 4365-4368.

Villegas, C. and van der Schaaf, H. (2011). Implementation of a pitch stability control for a wave energy converter. In Proc. $10^{\text {th }}$ Euro. Wave and Tidal Energy Conf. Southampton, UK.

WAMIT (2002). WAMIT user manual.

Weber, J., Costello, R., and Ringwood, J. (2013). Wec technology performance levels (tpls) - metric for successful development of economic wec technology. In Proc. $11^{\text {th }}$ European Wave Energy Conference. Aalborg, Denmark.

Whittaker, T. and Folley, M. (2012). Near-shore oscillating wave surge converters and the development of oyster. Phil. Trans. R. Soc. A, 345-364.

Wright, A., Beattie, W., Thompson, A., Mavrakos, S., Lemonis, G., Nielsen, K., Holmes, B., and Stasinopoulos, A. (2003). Performance considerations in a power takeoff unit based on a non-linear load. In Proc. $5^{\text {th }}$ European Wave Energy Conference. Cork.

Yemm, R., Pizer, D., and Retzler, C. (2002). Floating apparatus and method for extracting power from sea waves. US Patent No. 6476511.

Yuan, Z.D. and Huang, Z.H. (2010). An experimental study of inertia and drag coefficients for a truncated circular cylinder in regular waves. Journal of Hydrodynamics, 22, 318-323.

Zurkinden, A., Guerinel, M., Alves, M., and Damkilde, L. (2013). Theoretical investigation of a wave energy system by applying reactive control using stochastic analysis of the wave state. In Proc. 11th European Wave and Tidal Energy Conference. Aalborg, Denamrk. 